\title{
Cost of Illness Study of Regular Out Patient Department Diabetic in a Low Income Country: A Cross Sectional Study
}

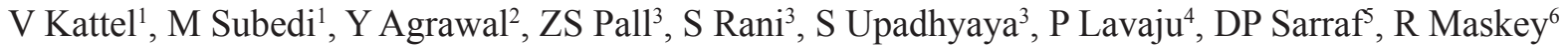 \\ ${ }^{1}$ Faculty, Department of Internal Medicine, BPKIHS, Dharan, Nepal, ${ }^{2}$ Faculty Department of Pathology, \\ BPKIHS, Dharan, Nepal, ${ }^{3}$ MBBS Department of Internal Medicine, BPKIHS, Dharan, Nepal, ${ }^{4}$ Head \\ Department of Ophthalmology, BPKIHS, Dharan, Nepal, ${ }^{5}$ Faculty Department of Pharmacology, \\ BPKIHS, Dharan, Nepal, ${ }^{6}$ Chair, Endocrinology Division, Department of Internal Medicine, BPKIHS, \\ Dharan, Nepal
}

\begin{abstract}
Background: The burden of Diabetes in South Asia is alarming as the prevalence is higher compared to other region, living cost is low after Sub Saharan Africa and health care system are in state of expanding to be more accessible and adequate.

Objectives: The objective of the study was to assess the direct cost of illness among diabetic patient regularly visiting at outpatient department (OPD) in BPKIHS.

Methods: This was a cross sectional study done in year 2018. 142 patients with at least nine visit per year were enrolled. The direct cost were calculated from the pattern of prescription of medications and laboratory investigations carried out over a year of the individual patient. The data were tabulated and analyzed.

Results: Among the 142 patients on $37.5 \%$ were in mono-therapy and $62.5 \%$ were in poly-therapy. The direct cost of illness was USD 103 per annum that includes drug and investigation cost expensed at OPD visit. The average indirect cost was USD 102 per annum including travel and food. Among 142 patient the cost of illness on inpatient due to DM was USD 85.47 per event.

Conclusion: The financial burden of being a diabetic in Nepal is high. Comprehensive quality care by expansion of health system and service with nominal charges to patient seems to be one of the challenges in Nepal.
\end{abstract}

Key Words: Burden, Cost of illness, Diabetes, Nepal

\section{Introduction}

Diabetes Mellitus (DM) is a metabolic disorder of multiple etiology characterized by chronic symptoms and signs of hyperglycemia with disturbances of carbohydrate, fat and protein metabolism resulting from defects in insulin secretion and/or insulin action. The global burden of DM has been increasing throughout the globe as a pandemic morbidity. WHO reports $8.8 \%$ prevalence of diabetic cases globally accounting 422 million adults at year 2014 and mortality due to DM as 1.5 million during year 2012. Obesity, sedentary life styles, stress, increase life expectancy and genetic

Corresponding author: Dr. Vivek Kattel, Faculty, Internal Medicine, BPKIHS,Dharan, Nepal. email: vivekkattel@ bpkihs.edu factors are driving force for the dramatic increase in the burden of DM. ${ }^{1}$ By 2017 US department of health and human services estimated 23.1 million diabetic patient in the United States with the cost burden of more than USD245 billion per year. ${ }^{2}$ The global cost of diabetes for 2015 was USD 1.31 trillion (95\% CI $1.28-1.36)$ or $1.8 \%(95 \%$ CI $1.8-$ 1.9) of global gross domestic product (GDP). ${ }^{3}$

Cost-of-illness on DM studies typically include direct and indirect costs of DM. Direct costs comprise all expenditures for the treatment of diabetes, including medication, hospital stays, and treatment of complications. Indirect costs are defined as productivity or production losses associated with morbidity and premature mortality. ${ }^{4}$ Thus DM is a 
cost threat disease with significant morbidity and mortality especially in geography where point of diabetic care are still being developed. There are challenges of diabetic care in developing world like political commitment not addressing adequacy in trained manpower, development of diabetic care unit that compromise different specialties, accessibility and affordability's of existing private based services. This study was conducted in one of the referral provincial governmental hospital of Republic of Nepal to estimate the direct and indirect cost of regularly visiting outpatient based diabetic patient.

\section{Methodology}

This was a cross sectional study conducted at BP Koirala Institute of Health Sciences (BPKIHS), Dharan, Nepal. Those diabetic patient who visit at least nine outpatient department per year were enrolled in the study. Considering $8.8 \%$ prevalence of diabetes in Nepal we calculated the sample size of 128 with $95 \%$ confidence interval and 95\% power of the study. Adding $10 \%$ as biases the final sample size was 142. A pretested questionnaire on case recording form (CRF) was used for the collection of the data. The confidentiality of the patients were maintained by generating a code system in CRF. The data were tabulated in Microsoft Excel Program 2007 and were analyzed by using Statistical Package for Social Sciences (SPSS) software version 11.5. Ethical clearance were taken from the Institutional Review Committee (IRC) of the institute. The direct cost were calculated from the pattern of prescription of medications and laboratory investigations carried out over a year of the individual patient. The indirect cost included were travel and food expenses and cost equivalent to productivity loss during that hospital visit.

\section{Results}

Among 142 cases the mean and median age was $56.7 \pm 12.4$ and 58 years respectively. Majority of the patient were Hindu by religion. Most of them were unemployed, had sedentary life style, consumed alcoholic beverage and tobacco (Table 1)
Table 1: Socio demographic characteristics $(n=142)$

\begin{tabular}{|c|c|c|}
\hline S.N & Demographic characters & Measurement \\
\hline 1. & $\begin{array}{l}\text { Age } \\
\text { 1. Mean } \\
\text { 2. Median }\end{array}$ & $\begin{array}{l}56.7 \pm 12.4 \\
58\end{array}$ \\
\hline 2 & Gender Female/Male & $0.9 / 1$ \\
\hline 3 & $\begin{array}{l}\text { Religion } \\
\text { 1. Hindu } \\
\text { 2. Muslim } \\
\text { 3. Buddhist } \\
\text { 4. Christian } \\
\text { 5. Others } \\
\text { Life style and Daily Activity } \\
\text { 1. Sedentary } \\
\text { 2. Mild to moderate } \\
\text { 3. Severe }\end{array}$ & $\begin{array}{l}116 \\
12 \\
9 \\
4 \\
1 \\
\\
\\
86 \\
49 \\
7\end{array}$ \\
\hline 4 & $\begin{array}{l}\text { Occupation } \\
\text { 1. Profession } \\
\text { 2. Semi-Profession } \\
\text { 3. Clerical, Shopkeeper, } \\
\text { Farmer } \\
\text { 4. Skilled Worker } \\
\text { 5. Semi-Skilled } \\
\text { 6. Unskilled } \\
\text { 7. Unemployed }\end{array}$ & $\begin{array}{l}9 \\
9 \\
\\
17 \\
8 \\
9 \\
7 \\
83\end{array}$ \\
\hline 5 & Family history of Diabetes & 52 \\
\hline 6 & $\begin{array}{l}\text { Living with diabetes } \\
\text { Mean duration of Diabetes } \\
\text { 1. Less than } 1 \text { year } \\
\text { 2. } 1 \text { to } 5 \text { years } \\
\text { 3. }>5 \text { - } 10 \text { years } \\
\text { 4. More than } 10 \text { years }\end{array}$ & $\begin{array}{l}6.4 \pm 5.2 \text { years } \\
11 \\
56 \\
47 \\
28\end{array}$ \\
\hline 7 & $\begin{array}{l}\text { Substance use } \\
\text { 1. Alcoholic beverage } \\
\text { a. Safe } \\
\text { b. Unsafe } \\
\text { 2. Nicotine }\end{array}$ & $\begin{array}{l}49 \\
14 \\
25 \\
76\end{array}$ \\
\hline
\end{tabular}

On examination more than $47 \%$ of these patients had BMI more than upper normal limit. About two third of the patients were screened for diabetic complications. Nephropathy (26.1\%) was the most common microvacsular complication detected. Tuberculosis $(45.45 \%)$ was the most common 
comorbid condition associated with diabetic patient (Table 2).

Table 2: Diabetes and its associated determinants $(n=142)$

\begin{tabular}{|c|c|c|}
\hline S.N. & Determinants associated with diabetes & Measurement \\
\hline 1 & $\begin{array}{l}\text { BMI } \\
\text { Mean BMI } \\
\begin{array}{ll}\text { 1. } & \text { Less than } 18.5 \\
\text { 2. } & 18.5-25 \\
\text { 3. } & >25-30 \\
4 . & >30-35 \\
5 . & >35\end{array}\end{array}$ & $\begin{array}{l}25.27 \pm 3.4 \\
3 \\
68 \\
57 \\
9 \\
5\end{array}$ \\
\hline 2 & $\begin{array}{l}\text { Screening for diabetic complications over last year } \\
\text { 1. No } \\
\text { 2. Yes } \\
\text { a. Eye Disease } \\
\text { b. Kidney disease } \\
\text { c. Heart disease } \\
\text { d. Vitamin deficiency } \\
\text { e. Joint \& Musculoskeletal disease } \\
\text { f. Genitourinary disease } \\
\text { g. Nerve disease } \\
\text { h. Foot disease } \\
\text { i. Brain disease } \\
\text { j. Skin disease }\end{array}$ & $\begin{array}{l}7(4.9 \%) \\
135(95.1 \%) \\
117 \\
108 \\
79 \\
92 \\
49 \\
37 \\
29 \\
13 \\
11 \\
9\end{array}$ \\
\hline 3 & $\begin{array}{l}\text { Prevalence of Micro vascular complications } \\
\text { 1. Retinopathy } \\
\text { 2. Nephropathy } \\
\text { 3. Neuropathy }\end{array}$ & $\begin{array}{l}67(47.18 \%) \\
31 \\
37 \\
29\end{array}$ \\
\hline 4 & Admission to the hospital due to diabetes related issue & $41(28.7 \%)$ \\
\hline 5 & $\begin{array}{l}\text { Presence of other disease } \\
\begin{array}{l}\text { 1. None } \\
\text { 2. Systemic HTN } \\
\text { 3. COAD } \\
\text { 4. CKD } \\
\text { 5. CAD } \\
\text { 6. Subclinical Hypothyroidism } \\
\text { 7. Tuberculosis }\end{array}\end{array}$ & $\begin{array}{l}26 \\
49 \\
12 \\
9 \\
7 \\
19 \\
64\end{array}$ \\
\hline
\end{tabular}


Among the 142 patients on anti-diabetic medication $37.5 \%$ were in mono-therapy whereas $62.5 \%$ were in poly-therapy (Table 3).

Table 3: Treatment Characteristics $(n=142)$

\begin{tabular}{|c|c|c|}
\hline S.N. & Treatment Characteristics & Measurement \\
\hline 1 & $\begin{array}{l}\text { Diabetic care } \\
\text { 1. Dietary and Lifestyle modification } \\
\text { 2. Anti-diabetic medications only } \\
\text { 3. Dietary modification and Anti-diabetic medications } \\
\text { 4. Dietary and Lifestyle modification and Anti-diabetic } \\
\text { medications }\end{array}$ & $\begin{array}{l}2(1.4 \%) \\
11(7.9 \%) \\
70(49.2 \%) \\
59(41.5 \%)\end{array}$ \\
\hline 2 & $\begin{array}{l}\text { Control of Diabetes throughout last nine visits } \\
\text { 1. Uncontrolled } \\
\text { 2. Partial controlled } \\
\text { 3. Fair controlled } \\
\text { 4. Very well controlled }\end{array}$ & $\begin{array}{l}3(2.1 \%) \\
8(5.8 \%) \\
57(40.1 \%) \\
74(52.1 \%)\end{array}$ \\
\hline 3 & $\begin{array}{l}\text { Change in anti-diabetic agents pattern }(n=140) \\
\text { No } \\
\text { Yes } \\
\text { 1. Monotherapy to polytherapy } \\
\text { 2. Monotherapy to other group of monotherapy } \\
\text { 3. Polytherapy to monotherapy }\end{array}$ & $\begin{array}{l}17(12.1 \%) \\
123(87.6 \%) \\
61(43.6 \%) \\
18(12.9 \%) \\
44(31.4 \%)\end{array}$ \\
\hline
\end{tabular}

Metformin (77.46\%) was most commonly prescribed drug followed by sulfonylureas (38.03\%) and DPP-4 inhibitors $(28.17 \%)$ (Table 4$)$. Out of $140,50(35.7 \%)$ patients reported adverse drug reactions (ADR) to the prescribed antidiabetic medications. 
Table 4: Prescription pattern and ADR of antidiabetic drugs $(n=140)$

\begin{tabular}{|l|l|l|l|l|l|}
\hline S.N. & $\begin{array}{l}\text { Anti-diabetic } \\
\text { drugs }\end{array}$ & $\begin{array}{l}\text { Monotherapy } \\
(\mathbf{n}=53)\end{array}$ & $\begin{array}{l}\text { Poly-therapy } \\
(\mathbf{n}=\mathbf{8 7})\end{array}$ & $\begin{array}{l}\text { Total (\%) } \\
\text { Adverse } \\
\text { Reaction (\%) }\end{array}$ \\
\hline 1. & Metformin & 31 & 79 & $110(78.57)$ & $28 / 110(25.4)$ \\
2. & Sulfonylurea & 2 & 52 & $54(38.57)$ & $7 / 54(12.9)$ \\
3. & Alpha glucosidase & 0 & 6 & $6(4.28)$ & 0 \\
& inhibitors & & 37 & $40(28.57)$ & $3 / 40(7.5)$ \\
4. & DPP-4 inhibitors & 3 & 2 & $2(1.42)$ & 0 \\
5. & Thiozolidinediones & 0 & $17(12.14)$ & $4 / 17(23.5)$ \\
6. & Insulin & 11 & 6 & $27(19.28)$ & $8 / 27(29.6)$ \\
7. & Insulin Analogue & 6 & 21 & &
\end{tabular}

The most common reason for change in anti-diabetic drug pattern was inadequate control of sugar profile (51\%) followed by cost issue (34\%) and drug intolerance ( $8 \%$ ) (Figure 1$)$.

Figure 1: Reason of change in prescription pattern of antidiabetic drugs $(n=77)$

\section{Reason of change in prescription pattern of antidiabetic drugs}

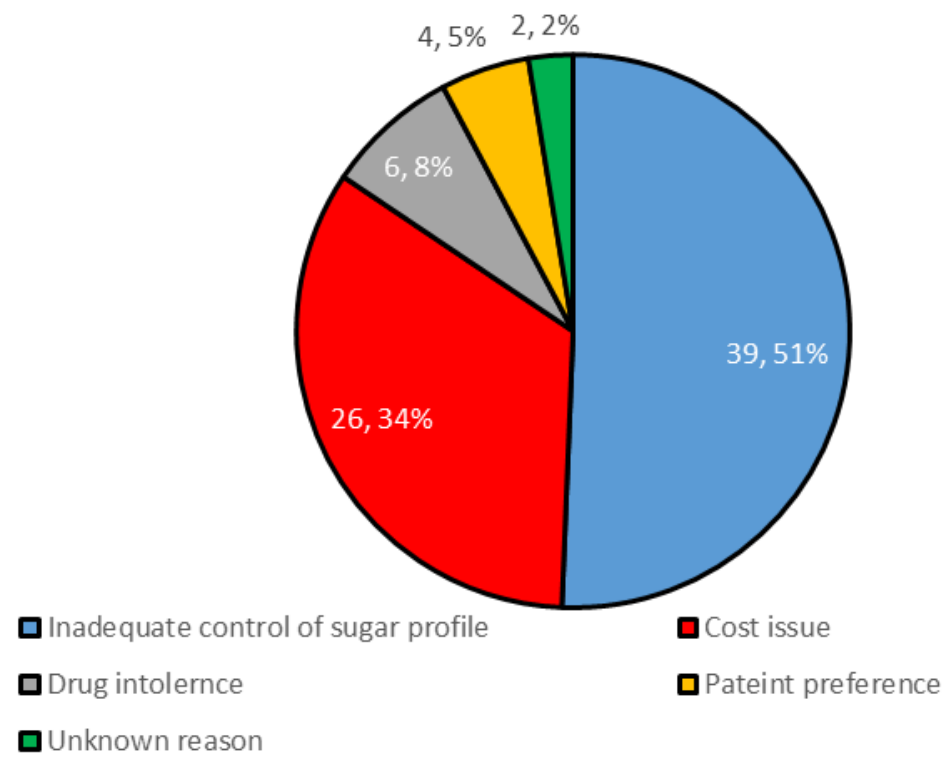

The average cost spent on drug and investigations was USD 73 per annum and USD 30 per annum respectively. The average indirect cost was USD 102 per annum. The average cost of illness for outpatient 
care was USD 205 per annum. Six patients (4.2\%) got admitted and the average inpatient cost was USD 85.47 per event (Table 5).

Table 5: Cost of treatment

\begin{tabular}{|l|l|l|}
\hline S.N. & Characteristics & Cost in USD per annum \\
\hline 1 & Average drug cost/annum & 73 \\
& 1. Metformin & 46.1 \\
& 2. Sulfonylurea & 67.7 \\
& 3. Alpha glucosidase inhibitors & 73.8 \\
& 4. DPP-4 inhibitors & 92.3 \\
& 5. Thiazolidinediones (Glitazones) & 40 \\
& 6. Insulin & 215.4 \\
& 7. Insulin Analogue & 410.3 \\
\hline 2 & Average investigation cost/annum & 30 \\
& Average inpatient cost/event & 85.47 \\
\hline 3 & Average indirect cost/annum & 102 \\
& 1. Travel cost & 30.8 \\
& 2. Food cost during travel & 20.5 \\
& 3. Loss of daily wages cost & 50.7 \\
\hline
\end{tabular}

\section{Discussions}

DM is a severe public health problem in Nepal. Diabetic care is being developed in this part of the world struggling to deliver comprehensive, quality treatment and services. Cost is a vital component for people with non-communicable disease including $\mathrm{DM}$ as treatment is expected to be lifelong. The economic burden resulting from diabetic care is a major concern for developing countries like Nepal. This is so because the burden of infectious disease is priority program in developing world. However burden of infectious and non-communicable disease is alarming in developing world. Lack of inadequate governmental health budget against non-communicable disease give space for private set up to invest on these arena however the cost of illness remains crucial for sustainable quality care. It is critical to have an understanding of the cost-of-illness of diabetes in order to develop and implement policies to reduce this cost. This study has estimated the direct and indirect cost-of-illness of diabetic care in patients visiting outpatient department on regular basis in a referral center in Eastern Nepal.

Our study showed a higher prevalence of DM in male gender. This could be due to better health care-seeking behaviors for males leading to their treatment at referral centers especially in developing world. Similar findings had been also reported from another Nepalese studies where the female to male ratio was $1: 1.02 .{ }^{5}$ Upadhyay et al had also reported a higher prevalence of DM in male gender. ${ }^{6}$ The study finding was different to Lisha et al in which a 
Cost of Illness Study of Regular Out Patient Department Diabetic... Jour of Diab and Endo Assoc of Nepal 2019; 3 (1): (16-25) ISSN Print 2594-3367 ISSN Online 2631-2107 high proportion female patients were diabetic. ${ }^{7}$

Mean age of the diabetic patients was 56 year in our study. A higher mean age of 59.81 years was reported in another study conducted in Nepal by Karki et al. ${ }^{8}$ Similar findings were also reported by Maskey et al in which average age was 55 year. $^{5}$ In contrast, a lower mean age of 49.14 years was reported by Upadhyay et al. ${ }^{6}$

In our study, most of the patients were unemployed, had sedentary life style, consumed alcoholic beverage and tobacco. Upadhyay et al had also documented that most of the diabetic patients (40.7\%) were unemployed, alcoholic and smoker. ${ }^{6}$ A cross-sectional study by Gautam et al reported association between strong alcohol and tobacco use and DM. ${ }^{9}$ In contrast to our study, higher percentage of the patients were physically active and exercised adequately, at least $30 \mathrm{~min} /$ day in a study conducted in South India.10 This is likely due to inclusion of only type $1 \mathrm{DM}$ in their study where as in our study both type 1 and $2 \mathrm{DM}$ were included. Older people are less active compared to the adults. Besides lack of education regarding benefit of physical activity over diabetes and causal risk could be another likely cause for this finding. Lack of physical activity is one of several risk factor for DM. ${ }^{5,11}$ Lifestyle modifications and regular exercise play an important role in diabetes management however antidiabetic drugs become unavoidable in many patients. Regular physical activity of at least 30 minute per day helps in achieving good glycemic control in DM. There is an urgent need to sensitize and motivate the patients about the benefits of regular exercise in management of DM. Almost half of the patients had higher body mass index (BMI). Similar finding on lifestyle modification was also reported by Mehta et al and Maskey et al. ${ }^{5,12}$

About two third of the patients were screened for diabetic complications. Nephropathy (27\%) was the most common microvacsular complication detected. In contrast to our study retinopathy was the commonest complication in a study conducted by Maskey et al. ${ }^{5} \mathrm{DM}$ is known to cause morbidity and mortality due to its micro-vascular and macrovascular complications. Diabetic retinopathy, nephropathy and neuropathy are common microvascular complications among poorly controlled and prolong diabetic patient. These complications has been associated with increased cost burden and decrease productivity. Prevention of these complications require package care of diabetes that involves multidisciplinary services which includes good control of blood sugar throughout the year, regular screening of these complications and early diagnosis and management of the complications. Around 50\% (67/135) screened diabetic patient had microvascular complication which is really alarming in resource limited set up. This fact exist among median age of 58 years diabetic cohort with mean duration of diabetes of 6.4 years. This could be challenge for health system especially with high prevalent geography (more than $8 \%$ prevalence in Nepal) to focus on training and treating more manpower against diabetic complication.

Tuberculosis $(45.45 \%)$ was the most common comorbid condition associated with DM followed by systemic hypertension (34.5\%). In contrast to this finding, hypertension $(21 \%)$ was the most common co-morbid condition in diabetic patients in Canada. ${ }^{13}$ The burden of latent tuberculosis is higher in developing world and risk of reactivation among diabetic is higher. However a study in India reported systemic hypertension as common comorbidity. ${ }^{14}$ This could be because tuberculosis could have been not subject of interest by the author though Nepal and India share similar prevalence of latent tuberculosis. The risk of having TB is three times higher in DM than in normal patients. ${ }^{15}$

Three fifth of the patients were on poly-therapy for DM. In contrast to our study, almost half of the patients $(51.4 \%)$ were on poly-therapy in a Canadian study. ${ }^{13}$ Poly-therapy is expected to increase the cost of treatment. Treatment in developing world are based upon cost factor. Higher doses of drugs are expected to be produce adverse drug effects. This could be associated with poor compliance and 
Cost of Illness Study of Regular Out Patient Department Diabetic... Jour of Diab and Endo Assoc of Nepal 2019; 3 (1): (16-25)
Journal of Diabetes and Endocrinology Association of Nepal

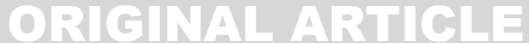

poor control of diabetes. As the disease progress poly-therapy remains as effective glycemic control tools in DM.

Metformin (79\%) was the most common drug prescribed. Sulphonylureas represented the next largest class of medications in our study. Similar finding was also reported by Das et al in which metformin (24.5\%) was prescribed more than sulphonylureas (19.9\%). ${ }^{16}$ A higher percentage of patients $(85.2 \%)$ were prescribed metformin in Canada.13 Metformin remains the most preferred oral antidiabetic drug throughout the globe the reason being cheaper, no weight gain and lesser hypoglycemic attack as compared to others. However dyspepsia, intolerance and methycobalamine deficiency have been commonly associated with metformin. In contrast to our finding sulfonylurea was the most commonly prescribed antidiabetic drug in India. ${ }^{17}$ Guidelines recommend metformin as first-line treatment for DM. ${ }^{18}$ The percentage of dipeptidyl peptidase-4 (DPP-4) prescription in our study was extremely low compared with that in Japan where $34.6 \%$ prescription consisted of DPP4. ${ }^{19}$ This could be because of cost issue.

Our study found that the average cost of DM for outpatient care was USD 205 per annum. In contrast to our study, a higher cost was reported by Shrestha et al where total cost incurred in the treatment and care of DM per annum was USD $445 .{ }^{20}$ The higher cost was due to fact that their study was conducted in private diabetic clinics. Mukherjee et al had reported that financial constraints was second most common cause for non-compliance to antidiabetic drugs in India. ${ }^{21}$ Similar annual mean cost of USD 197 had been reported by Khowaja et al. ${ }^{22}$ Total annual healthcare costs for diabetic care was USD15,175 in 2012 in the USA. ${ }^{23}$ This reflect vast difference in cost of illness in diabetic care in resource limited setup and developed nations. The point of care facilities for diabetic patients in Nepal are inadequate and inaccessible. ${ }^{24}$ This is likely to increase the direct and indirect cost of illness in terms of diagnosed at late stage and expenses

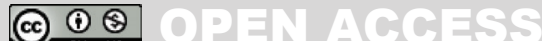

made to travel respectively. Diabetes imposes a large economic burden on the society to all types of community it remains lesser priority health issue in developing nation. The extensive treatments for diabetes and its complications account for much of the costs, making it one of the most expensive diseases to treat in many parts of the world..$^{25}$

Nepal's GDP Per Capita was 1,003.64 USD in Jul $2018 .{ }^{26}$ Nepal spends only $6 \%$ of its GDP on health care. ${ }^{27}$ The direct cost of managing diabetic at outpatient department in Nepal is 103 USD which accounts for $2.18 \%$ of GDP of Nepal (25.47 billion USD) assuming $8.4 \%$ as diabetic prevalence in Nepal that is 555 million USD. The investment by government in diabetic care is demands increase in health budget by more than one third of present health budget. Comprehensive quality care at low cost to patient seems to be one of the challenges in developing nation like Nepal. ${ }^{24}$ Thus diabetic care in public hospitals had large space to advance in Nepal. Absence of adequate multidisciplinary diabetic care point is barrier against accessible quality health care services. Government and private healthcare insurance do not cover the diabetic care in Nepal therefore these patients have to pay from their pocket to avail the acquired healthcare services, travelling cost and other indirect cost related to diabetic care.

The limitation of the study was that the diabetes patients were selected from only one hospital of Eastern Nepal and hence the study findings may not be able to generalize to the entire diabetic population of the country.

\section{Conclusions}

There is a high cost burden on the patient with DM in Nepal as the cost is not covered by health insurance. Lack of political commitment on investment is likely to deprive diabetic patient from cost effective quality diabetic care. This would land up with higher rate of conversion to complications that would further increase the cost of illness on diabetes in developing world.

Conflict of Interest: The author declares no conflict 
Cost of Illness Study of Regular Out Patient Department Diabetic...

Jour of Diab and Endo Assoc of Nepal 2019; 3 (1): (16-25)

ISSN Print 2594-3367 ISSN Online 2631-2107

of interest during this research activity.

\section{References}

1. Global Report on Diabetes on World Diabetes Day, 2015. [Available at http://apps.who.int/iris/bitstream/ handle/10665/204871/9789241565257_eng. pdf. (Accessed on 4th November, 2018.) )].

2. American Diabetes Association. Economic costs of diabetes in the US in 2012. Diabetes Care. 2013; 36(4):1033-1046.

3. Christian Bommer, Esther Heesemann, Vera Sagalova, Jennifer Manne-Goehler, Rifat Atun, Till Bärnighausen, Sebastian Vollmer. The global economic burden of diabetes in adults aged 20-79 years: a cost of illness study. Lancet Diabetes Endocrinol. 2017; 5(6):423-430.

4. Seuring T, Archangelidi O, Suhrcke M. The economic costs of type 2 diabetes: a global systematic review. Pharmacoeconomics 2015; 33(8):811-831.

5. Maskey R, Shakya DR, Sharma SK, Karki P, Lavaju P, Baranwal JK. Comparison of complications in diabetic outpatients with or without mental illness. Indian $\mathrm{J}$ Endocrinol Metab. 2013; 17(Suppl 1):S313-5.

6. Upadhyay DK, Ibrahim MI, Mishra P, Alurkar VM, Ansari M. Does pharmacist-supervised intervention through pharmaceutical care program influence direct healthcare cost burden of newly diagnosed diabetics in a tertiary care teaching hospital in Nepal: a non-clinical randomised controlled trial approach. Daru. 2016;24:6.

7. Lisha Jenny John, Mohammed Arifulla, Jayadevan Sreedharan, Jayakumary Muttappallymyalil, Rajdeep Das, Jenny John, et al. Age and gender-based utilization pattern of antidiabetic drugs in Ajman, UAE. Malaysian J Pharmaceut Sci 2012; 10(1):7985.

8. Karki DB, Yadava SK, Pant S, Thusa N, Dangol E, Ghimire S. Prevalence of Sensory Neuropathy in Type 2 Diabetes Mellitus and Its Correlation with Duration of Disease. Kathmandu Univ Med J (KUMJ). 2016;

\section{4(54):120-124.}

9. Gautam A, Bhatta DN, Aryal UR. Diabetes related health knowledge, attitude and practice among diabetic patients in Nepal. BMC Endocr Disord 2015; 15:25.

10. Joseph M, Shyamasunder AH, Gupta RD, Anand V, Thomas N. Demographic details, clinical features, and nutritional characteristics of young adults with Type 1 diabetes mellitus - A South Indian tertiary center experience. Indian J Endocrinol Metab. 2016; 20(6):799804.]

11. Sharma SK, GhimireA, Radhakrishnan J, Thapa L, Shrestha NR, Paudel N et al. Prevalence of hypertension, obesity, diabetes, and metabolic syndrome in Nepal. Int J Hypertens 2011; 2011:821971.

12. Mehta RS, Karki P, Sharma SK. Risk factors, associated health problems, reasons for admission and knowledge profile of diabetes patients admitted in BPKIHS. Kath Univ Med J. 2006; 4:11-13.

13. Greiver M, Williamson T, Barber D, Birtwhistle R, Aliarzadeh B, Khan S et al. Prevalence and Epidemiology of Diabetes in Canadian Primary Care Practices: A Report from the Canadian Primary Care Sentinel Surveillance Network. Can J Diabetes. 2014;38(3):179-175.

14. Dashputra AV, Badwaik RT, Borkar AS, Date AP, Kalnawat NR. Pattern of Antidiabetic Drugs used in Outpatient and Hospitalized Patients in a Tertiary Health Institute of Central India. J Cont Med A Dent. 2014;2(3):48-54.

15. Jeon C Y, Murray M B. Diabetes mellitus increases the risk of active tuberculosis: a systematic review of 13 observational studies. PLOS Med. 2008; 5:e152.

16. Das P, Das BP, Rauniar GP, Roy RK, Sharma SK. Drug utilization pattern and effectiveness analysis in diabetes mellitus at a tertiary care centre in eastern Nepal. Indian J Physiol Pharmacol. 2011;55(3):272-80.

17. R. Ramesh, Subash Vijaya Kumar, S. Gopinath, B. Gavaskar, G. Gandhiji. Diabetic knowledge of rural community and drug utilization pattern in a tertiary care hospital. Int J Pharm Life Sci. 
2011;2(1):531-535.

18. American Diabetes Association. Standards of Medical Care in Diabetes 2010. Diabetes Care 2010; 33:S11e61.

19. Oishi M, Yamazaki K, Okuguchi F et al. Changes in oral antidiabetic prescriptions and improved glycemic control during the years 2002-2011 in Japan (JDDM32). J Diabetes Investig. 2014; 5:581-7.

20. Shrestha N, Lohani SP, Angdembe MR, Bhattarai K, Bhattarai J. Cost of diabetes mellitus care among patients attending selected outpatient clinics. J Nepal Med Assoc. 2013;52(190):343-8.

21. Mukherjee S, Sharmasarkar B, Das KK, Bhattacharyya A, Deb A. Compliance to antidiabetic drugs: observations from the diabetic clinic of a medical college in kolkata, India. J Clin Diagn Res. 2013;7(4):661-5.

22. Khowaja LA1, Khuwaja AK, Cosgrove P. Cost of diabetes care in out-patient clinics of Karachi, Pakistan. BMC Health Serv Res. 2007;7:189.
23. Weng W, Liang Y, Kimball ES, Hobbs T, Kong S, Sakurada B et al. Drug usage patterns and treatment costs in newly-diagnosed type 2 diabetes mellitus cases, 2007 vs 2012: findings from a large US healthcare claims database analysis. J Med Econ. 2016;19(7):655-62.

24. Kattel V, Maskey R, Lavaju P , Taparia R, Agrawal $\mathrm{Y}$. Challenges of being a diabetic in Nepal. Jour of Diab and Endo Assoc of Nepal 2018; 2 (2) (1-2)

25. Zhang P, Gregg E. Global economic burden of diabetes and its implications. Lancet Diabetes Endocrinol. 2017;5(6):404-405.

26. Nepal GDP per Capita. CEIC, 2018. Available at https:// www.ceicdata.com/en/indicator/ nepal/gdp-per-capita (Accessed on November 5, 2018.)

27. The World Bank (2018). Current health expenditure ( $\%$ of GDP). Available from: https://data.worldbank.org/indicator/SH.XPD. CHEX.GD.ZS?locations=NP\&name_desctrue [cited November 5, 2018.]. 